\title{
OS BRASILEIROS NA FRANÇA
}

\author{
Gisele Maria Ribeiro de Almeida*
}

“Estamos fugindo da década perdida pelos portões de embarque dos aeroportos internacionais". Foi dessa forma que Teresa Sales, em meados da década de 1990, representou o então recente movimento de emigração de brasileiros. Se a chamada década perdida acabou, o mesmo não se pode dizer do fluxo de brasileiros que se aventuram a "tentar a vida e a sorte" em outros países, notadamente EUA, Japão e alguns países europeus. Segundo o Ministério das Relações Exteriores (MRE) do Brasil, a presença de brasileiros no exterior tem crescido de forma constante nas últimas duas décadas. E isso tem ocorrido, cabe frisar, a despeito do melhor desempenho da economia nacional.

A bibliografia sobre o tema das migrações internacionais contemporâneas tem se interessado por essas questões, e uma análise dessa produção mostra que as condições do país de origem como superpopulação e pobreza não são mais consideradas suficientes para explicar os deslocamentos atuais.

* Doutoranda em Sociologia no IFCH/Unicamp, desenvolve o projeto de pesquisa "Seletividade migratória e capital cultural na migração de brasileiros para a França" que integra o projeto temático "Observatório das Migrações em São Paulo" coordenado pela Profa. Dra. Rosana Baeninger. Ambos projetos são financiados pela Fundação de Amparo à Pesquisa do Estado de São Paulo. 
| 44 |

Os Brasileiros na França

Há outros fatores e condições mais relevantes para se entender o crescimento e a manutenção dos fluxos, como a presença de investimentos estrangeiros. Saskia Sassen (1993) é uma autora que demonstra o equívoco das análises sobre o fenômeno migratório, que se mantêm limitadas aos condicionantes da origem (como superpopulação, pobreza e estagnação econômica) e por isso o enxergam por uma ótica nacional. Sua proposta é que a compreensão destes fluxos exige uma análise que contemple fatores internacionais. Sassen chega a afirmar que o processo atual de imigração nos EUA, por exemplo, pode ser visto como uma consequência de suas atividades econômicas em terras estrangeiras. Nas migrações contemporâneas não se confirma a hipótese de que a estagnação econômica gera a migração, como exemplifica o caso da Coréia do Sul, que a despeito de apresentar elevados índices de crescimento e emprego, registrou um forte fluxo emigratório para os EUA.

Ainda que superpopulação, pobreza e estagnação econômica possam gerar pressões migratórias, a migração em larga escala depende de processos adicionais, que se cruzam e transformam as condições originárias em uma situação propícia para a migração. Para Sassen há processos mediadores que vinculam os países e contribuem para novas correntes migratórias, como os investimentos estrangeiros e a presença de empresas multinacionais. Esses elementos transformam a base econômica dos países, rompendo com suas economias tradicionais (atividades de subsistência e industriais adaptadas ao mercado local); consequentemente, as formas de trabalho adotadas por aquele contexto se desorganizam. No entanto, essas mudanças não conduzem a migração em todos os casos. Como explicar então a seletividade presente no fenômeno migratório contemporâneo? Para Sassen, a resposta está nos vínculos objetivos e ideológicos que se criam entre países de origem e destino dos migrantes, como o investimento estrangeiro, a ocidentalização cultural, política migratória liberal e tradição de migração.

O argumento de Alejandro Portes (1999) alimenta a idéia de que esses vínculos viabilizam e promovem fluxos. Segundo 
o autor, a pobreza e as diferenças salariais entre os países não podem ser tomados em si como aspectos elucidativos do fenômeno migratório, dado que os mais pobres raramente emigram. A maioria dos migrantes internacionais faz parte de setores sociais que foram mais afetados pelo hiato entre as expectativas de consumo (padrão de vida moderna) e os meios econômicos para realizá-las. Para Portes, as correntes migratórias em geral se dirigem de países periféricos para aqueles países centrais com os quais possuem maiores vínculos históricos e que são normalmente responsáveis pela difusão de novos desejos e aspirações.

Outra perspectiva fundamental de análise do fenômeno migratório é ofertada pelo referencial das chamadas redes sociais (MASSEY et al, 1987). Quanto à aparente contradição, entre a melhor situação econômica e a manutenção da emigração, essa abordagem é elucidativa e, permite compreender o processo pela dinâmica social da migração. A idéia básica, é que imigrantes pioneiros estabelecem vínculos entre origem e destino, estreitando relações e viabilizando parcerias diversas. $\mathrm{O}$ começo do fluxo engendra, nesta perspectiva, uma infra-estrutura social, como conhecimento sobre possibilidades de trabalho, lugar para se alojar, etc., capaz de sustentar um movimento maior. Assim, ao longo do tempo, os laços entre os locais de origem e destino se dinamizam. A rede social criada diminui os custos envolvidos num projeto migratório, levando a um efeito catalisador da própria rede, que tende a se fortalecer e ao mesmo tempo encorajar novos projetos, resultando em volumosos fluxos migratórios entre certas localidades de origem e de destino. Essa aproximação potencializa novos deslocamentos que tendem, com o tempo, a atingir certa autonomia em relação a variáveis econômicas, como situação do mercado de trabalho, que comumente se associam à mobilidade socio-espacial da população.

É por isso que pesquisadores ligados ao tema da migração, sugerem que a análise das migrações internacionais considere a articulação entre as condições dos locais de origem (os chamados fatores de expulsão) e a situação das áreas de destino (os fatores de atração). Longe de se resumir a uma função simplista, essas 
|46 |

Os Brasileiros na França

contribuições apontam a relevância de se buscarem os elos entre os pontos dos fluxos, pontes erigidas por condições econômicas, políticas e culturais.

No caso da emigração de brasileiros, as últimas estatísticas disponibilizadas pelo Ministério das Relações Exteriores (MRE) do Brasil, em setembro de 2009, registraram mais de 3 milhões de brasileiros vivendo no exterior. A maior comunidade está nos Estados Unidos, que receberam mais de $40 \%$ deste contingente. Paraguai e Japão concentram respectivamente $10 \%$ e $9 \%$ dos brasileiros emigrantes (no caso do Paraguai, é um fluxo bastante específico, ligado à expansão da fronteira agrícola). Os dados agrupados para a Europa indicam a participação expressiva do velho continente, constituindo residência de $27 \%$ dos brasileiros que estão no exterior.

Buscando os vínculos promotores desses fluxos, percebe-se que a escolha de alguns destinos dos brasileiros pode ser compreendida a partir das relações e afinidades entre os países envolvidos. O Japão, por exemplo, é o país de origem de muitos imigrantes que se estabeleceram no Brasil, reforçando vínculos e intercâmbios culturais entre esses países. O fluxo Japão-Brasil do início do século XX gerou descendentes no país, que hoje constituem o movimento de refluxo Brasil-Japão.

Esse vínculo histórico também se manifesta no caso da Itália. O Brasil recebeu um expressivo contingente de imigrantes italianos no final do século XIX. Muitos dos seus descendentes, hoje são reconhecidamente cidadãos italianos. No contexto de emigração brasileira, estas relações pretéritas constituem pontos importantes para a formação das redes entre os dois países.

Os dados sobre a população estrangeira residente em Portugal, disponibilizados pelo Serviço de Estrangeiros e Fronteiras (SEF) daquele país, mostram que a maior parte desta possui nacionalidade brasileira, representando quase um quarto dos estrangeiros que lá vivem. O fluxo Brasil-Portugal retoma a questão de relações históricas e, neste sentido, fortalece o argumento dessas conexões como dinamizadoras dos fluxos de pessoas. 
Compreender a emigração de brasileiros para outros destinos na Europa, como Espanha, Alemanha e França requer estudos mais aprofundados e uma problematização mais exigente, considerando-se que as relações entre o Brasil e tais países são mais difusas e menos estudadas. Demanda a construção de hipóteses capazes de explicar a seletividade migratória, seja pela causa da saída do país de origem, seja pela eleição do país destino.

Desse modo, para o caso dos brasileiros na França, a questão se apresenta da seguinte forma: quais são as condições que têm contribuído para a imigração brasileira na França? Como se pode explicar o fluxo Brasil-França nas últimas décadas? Quem são estes brasileiros e como vivem na França?

Em linhas bem gerais, responder essas questões é o objetivo de uma pesquisa ainda em execução. Neste artigo, serão discutidas as hipóteses orientadoras desta investigação bem como algumas das reflexões que as sustentam. A perspectiva adotada põe em evidência a noção de seletividade migratória nessa investigação, ao operar com a hipótese de que na migração brasileira para França há características singulares, que engendram a especificidade do fluxo. Nesse sentido, cabe discutir o que se entende por seletividade migratória e quais são suas implicações analíticas para a compreensão do fenômeno em questão.

Segundo Paul Singer (1973), a mobilidade espacial da população não pode ser desvinculada do contexto histórico no qual ocorre, dado que as migrações, como qualquer outro fenômeno social, são sempre historicamente condicionadas, e causadas por um processo global de mudança. Por isso, o fenômeno migratório não pode ser analisado de forma hermética, pois são as transformações estruturais que causam a migração. Essas "causas" são condicionantes capazes de estimular os deslocamentos, e precisam ser diferenciadas dos "motivos", aqueles que os indivíduos alegam ter para migrar.

Via de regra, a decisão de migrar de um indivíduo resulta da avaliação de que há mais benefícios em partir do que em ficar, ou seja, no horizonte que serve de base à decisão de migrar, os 
| 48 |

Os Brasileiros na França

aspectos positivos vislumbrados no lugar de destino superam aqueles vivenciados na origem. É importante ressaltar que aceitar essa proposição não é o mesmo que partilhar dos referenciais da microteoria neoclássica - Soares (2004) fornece um resumo das principais perspectivas teóricas utilizadas para analisar as migrações internacionais contemporâneas, inclusive neoclássicas - que compreende a ação humana sempre baseada em escolhas racionais, fundamentadas em análises de custos versus benefícios. O importante do argumento é que a causa da migração está na origem e não no destino. A implicação disso é que a compreensão de um fluxo exige que consideremos os fatores de expulsão, os quais estão relacionados a processos econômicos que alteram a divisão social do trabalho.

Os fatores de expulsão tornam outras localidades atrativas, mas deve-se dizer que esses fatores não são os mesmos para os diferentes grupos sociais. É por isso que a situação de classe é evocada por esta perspectiva analítica, na qual origem e destino se ligam de forma a espelhar a seletividade do processo migratório. Seletividade migratória, neste entendimento, é uma noção usada para se referir às formas pelas quais as causas estruturais capazes de engendrar uma nova distribuição espacial da população repercutem no interior de classes sociais distintas, isto é, como causa estrutural, tal ocorrência abrange e se refere a toda sociedade. No entanto, não são todos que migram, e nem todos que migram seguem o mesmo sentido. Como explicar então essa seleção de quem migra e para onde migra?

Incorporar a seletividade, em uma pesquisa que se volta a explicar um determinado fluxo migratório exige maior ênfase nos chamados "fatores de atração", pois é no destino que podemos visualizar a dispersão do comportamento típico do grupo. No caso das migrações internacionais, o alvo do projeto emigratório evidencia aspectos da seletividade do fluxo na medida em que pesquisando o universo de imigrantes com origem comum é possível saber como estes tomaram conhecimento sobre o país destino, em qual etapa do ciclo vital estão, etc. 
O objetivo de uma orientação analítica deste tipo é identificar as causas que explicam a emigração de brasileiros ao mesmo tempo que se pretende reconhecer os motivos que orientam o projeto migratório para a França. Considerando as especificidades desses dois países, é preciso buscar os elementos seletivos da migração desde a saída de uma determinada localidade no Brasil, passando pelo grupo social que migra (nível educacional, ocupação, sexo, idade), até as estratégias para a concretização do projeto migratório.

Por outro lado, as relações econômicas e culturais entre os dois países, e as representações sociais sobre a França que se difundem e se instituem no Brasil e alcançam certos grupos sociais, são um ponto de partida para o estabelecimento das relações entre o Brasil e a França. A influência cultural francesa não pode ser subestimada, até mesmo porque a política externa francesa sempre foi pautada em grande medida pela difusão cultural. Em livro que analisa o "Ano do Brasil na França", Amaral (2008) explicita que a cooperação cultural sempre teve o papel de facilitador da difusão cultural francesa no exterior. A Aliança Francesa, com atuação em 138 países atualmente, é uma evidência deste fenômeno. A instituição foi criada no final de século XIX com a missão de ensinar a língua francesa, favorecer intercâmbios culturais e científicos e difundir a cultura francesa.

No que se refere ao Brasil em particular, a história das relações franco-brasileiras começa ainda no século XVI, com o projeto de Villegaignon de criar uma colônia no país. Mais tarde, a Missão Artística Francesa de 1816 semeou idéias e deixou marcas profundas no Brasil ao longo do século XIX. A própria concepção da Nação Brasileira está bastante relacionada à influência dos ideais iluministas franceses. Durante o século XX, os laços entre Brasil e França foram reforçados, sendo notável a fascinação e a admiração que a França exerceu sobre diversos e importantes estratos brasileiros, especialmente em certos meios intelectuais e artísticos. No âmbito universitário e acadêmico, projetos de parceria científica foram essenciais na formação e na estruturação de importantes institutos e universidades no Brasil, como é 
|50|

Os Brasileiros na França

o caso da Universidade de São Paulo (KECHICHIAN, 2009; TAVARES, 1979).

Esse processo gerou uma rede muito forte de francófilos no país: no caso das universidades, essa francofilia provavelmente estimula a ida de brasileiros para estudar na França. Débora Mazza (2009) analisa os intercâmbios acadêmicos internacionais, e mostra que os EUA, a Inglaterra e a França são os principais destinos de bolsistas brasileiros que estudam no exterior. Os Estados Unidos são o maior receptor de bolsistas da Capes em quase todas as áreas; a exceção é o caso das Ciências Sociais no qual o principal país de destino é a França.

Segundo o Centro Franco-Brasileiro de Documentação Técnica e Científica (CenDoTec) instituição vinculada ao Ministério Francês de Relações Exteriores e Europeias cuja missão é apoiar a cooperação científica, universitária e tecnológica, facilitando e desenvolvendo o fluxo de informações entre a França e o Brasil, mais de mil brasileiros vão a cada ano estudar na França nos níveis de graduação e pós-graduação. Diversos estudos e pesquisas se dedicaram a examinar esse intercâmbio científico (CANÊDO e GARCIA, 2004; MARTINS, 2005; MUÑOZ, 2009).

Desde meados da década de 1990, as parcerias econômicas e políticas entre o Brasil e a França ganharam fôlego, e segundo o próprio Ministério de Assuntos Estrangeiros da França, o aprofundamento das relações com o Brasil é hoje uma política estratégica para o país. De acordo com o economista francês François Chesnais (1996), com exceção de países da Organização para a Cooperação e Desenvolvimento Econômico (OCDE), pode-se constatar uma presença significativa do investimento direto estrangeiro francês no Marrocos, no Brasil e na Tunísia. Atualmente, revistas econômicas têm dado destaque para a atuação de empresas francesas no Brasil como Renault, Valeo, Michelin, Grupo Accor, Danone, Carrefour, Leroy Merlin, FNAC, etc. e apontam que as parcerias tendem a se fortalecer e deverão estimular ainda mais projetos de cooperação diversos. Os fluxos de pessoas entre os dois países devem acompanhar esse processo 
e ser também dinamizados. E, no que tange a esse tema, os estudos são escassos.

Ângela Xavier de Brito, socióloga e pesquisadora brasileira radicada na França, realizou algumas pesquisas sobre estudantes brasileiros naquele país. Em uma delas, analisou as características sociais desses grupos comparando dois momentos distintos. Uma primeira investigação, realizada nos anos 1980, teve como público-alvo os estudantes brasileiros que foram à França para fazer o doutorado integralmente, com quatro anos de permanência no mínimo. Posteriormente, nos anos 1990, foi realizado um segundo estudo com 24 bolsistas num contexto de instituição das "bolsas sanduíche", em que o tempo de permanência na França diminui, alterando-se também o perfil do estudante (XAVIER DE BRITO, 2000).

Pode-se dizer que historicamente os brasileiros tinham uma reputação de elite intelectual, um tipo de reconhecimento que esteve associado ao acolhimento, por parte da França, dos estudantes refugiados da ditadura militar e, mais tarde pesquisadores, atraídos pelas universidades francesas. No entanto, uma reportagem realizada em 2005, pela Radio France Internacionale, evocou o perfil elitista do brasileiro na França, mas reconheceu uma nova orientação, apontando que nos últimos anos o país teria se tornado o destino de brasileiros que migram por motivações econômicas ${ }^{1}$. Neste sentido, a França seria uma "porta de entrada" para a Europa, em função das restrições para entrar em destinos-alvos como Inglaterra ou Espanha.

Os dados de 2009 do MRE apontaram que havia cerca de 60 mil brasileiros vivendo no território francês. As estimativas de 2008 tinham registrado um número bastante inferior: entre 20 e 30 mil. Ao que parece, o fluxo está em ascensão.

${ }^{1}$ VALENTE, Pamela. "Os brasileiros na França". In: Rádio França Internacional, 07/07/2005. Disponível em <www.rfi.fr/actubr/articles/067/ article_102.asp >. Acesso em: 05/08/2008. 
| 52 |

Os Brasileiros na França

Ainda que a França possa ser apenas um destino provisório para alguns brasileiros, a seletividade dessa migração continua sendo um ponto válido para questionamento. E se, como sugere Portes (1999), o migrante seleciona seus países de destino pelos vínculos históricos que se associam à difusão de certos desejos e aspirações, o desafio de uma pesquisa que pretende analisar o fluxo Brasil-França é encontrar tais elos e saber quais são os "desejos e aspirações" que estão motivando essas migrações.

Como foi discutido previamente, as redes sociais constituem um referencial analítico do estudo da migração internacional, que articulado a outras interpretações teórico-metodológicas, pode permitir análises profícuas acerca das especificidades da imigração brasileira na França. A abordagem das redes sociais, como fenômeno que se alia ao projeto migratório, incorpora em alguns estudos o conceito de capital social, entendido como os benefícios trazidos aos indivíduos em função do pertencimento a certas redes ou grupos sociais, inserção esta que viabiliza maiores recursos e informações. A problematização teórica da questão migratória tem recorrido à noção de capital social para entender e pensar o papel do acesso a determinados bens e oportunidades para a compreensão do êxito da experiência migratória, que, por sua vez, promove a consolidação e o fortalecimento da rede.

Muitas vezes, o conceito de capital social utilizado nas pesquisas não considera que as relações de poder (e a consequente estratificação social) são essenciais na constituição das possibilidades de inserção nessas redes, resultando pelos condicionantes pretéritos e estruturais em limitações distintas e desiguais. A abordagem de Pierre Bourdieu (1998), por outro lado, reconhece que a posição ocupada na hierarquia social e, portanto, a quantidade de capital (econômico, cultural e social) que o indivíduo possui são vitais para a compreensão de sua posição no espaço social e seu o acesso às vantagens e às oportunidades disponíveis neste espaço.

Neste sentido, essa investigação sobre imigração brasileira na França considera que competências, habilidades e saberes (capital cultural) são variáveis importantes para a compreensão 
do processo de emigração de brasileiros para a França e para o tipo de inserção desses brasileiros na sociedade francesa (capital social), a partir do delineamento dos elementos teóricos que configuram a seletividade migratória nesse fluxo. E, aqui, não se ignora, evidentemente, o caráter intrínseco do capital econômico para a determinação do capital cultural e social.

Desta forma, para entender esta migração internacional do ponto de vista da origem, a noção da seletividade migratória se vincula ao conceito de capital cultural de Bourdieu. Para esse autor, o conceito de capital cultural se contrapõe à concepção de capital humano (aptidões resultantes de uma "natureza") e torna-se assim uma ferramenta heurística mais adequada para revelar como essas "aptidões" são engendradas pela dedicação, subordinada ao tempo disponível e aos recursos capazes de viabilizá-la, constituindo-se desta forma num processo que indica o acesso e/ou a posse de capital cultural, processo este determinado por estruturas sociais e por práticas internalizadas.

É hipótese da pesquisa que a base da rede social que liga os dois países tem um forte componente simbólico e é bastante singular, por isso as noções de capital social e cultural serão tomadas como referência para pensar o sentido específico do fluxo Brasil-França e a seletividade que atua neste processo. Isso se faz perscrutando em que medida os brasileiros que escolhem a França como destino e que obtêm sucesso nessa experiência se orientam em função de interesses sociais e culturais, explorando a influência que o capital social e cultural exerce para o êxito ou não do projeto migratório.

A situação do imigrante no destino é um reflexo da integração e do tipo de incorporação do imigrante naquela sociedade. Para discutir a inserção econômica dos imigrantes, Bryan Roberts (1995) considera os aspectos típicos deste ajuste, tais como: a nacionalidade do migrante, nível de instrução e qualificação profissional, mas, sua contribuição mais interessante se refere à incorporação da idéia de que as expectativas do imigrante em relação à duração da experiência migratória são decisivas para o seu ajustamento na sociedade de destino. $\mathrm{O}$ autor 
| 54 |

Os Brasileiros na França

reconhece a importância da constituição das redes sociais entre os imigrantes de uma mesma nacionalidade para sua inserção no mercado de trabalho, todavia sua ênfase recai no fato de que as expectativas em relação à experiência migratória orientam o planejamento de curto e de longo prazo e de que esses planos se transformariam em mais ou menos capital social.

De acordo com o autor, há uma relação entre a incerteza quanto ao futuro e a possibilidade de atingir metas, o que é fundamental para a determinação do comportamento do migrante (aqueles que pensam em passar pouco tempo, por exemplo, não fazem investimentos de longo prazo como solicitar a naturalização). As expectativas temporais são individuais, mas também recebem influência dos grupos e das redes de relacionamento nos quais os imigrantes se inserem. Essas temporalidades, no original socially expected durations, que influem na inserção do imigrante não são homogêneas, dependem de múltiplas e às vezes conflituosas expectativas em relação ao tempo de duração da experiência migratória. As expectativas que derivam do local de origem e do local de destino podem ser divergentes, por exemplo, de um lado compromissos e relações que orientam a permanência da condição migratória e, por outro, apelos e exigências que demandam o retorno ao país de origem. Além disso, não é possível desconsiderar as expectativas formais das restrições legais impostas pelo país receptor como o vencimento de visto de residente, dificuldades para obtenção de visto de trabalho, entre outros empecilhos.

A imigração envolve sempre uma expectativa temporal, relativa à duração da permanência no destino e à questão do retorno. Nesse sentido, seria interessante considerar alterações nessa expectativa, quando ocorre o desejo de permanência e o estabelecimento definitivo no destino, e verificar como essa intenção repercute na demanda por direitos sociais e pela própria cidadania francesa. Também é interessante contrastar essas demandas com a expectativa temporal da política migratória francesa, pois, como é notório, a presença de estrangeiros em países europeus está constantemente sendo criticada, estimulando 
políticas migratórias e de nacionalização cada vez menos tolerantes.

Esse "temor" em relação ao estrangeiro e ao imigrante tem inclusive influenciado o cenário político francês. Para Rossana Rocha Reis (1999), o fato de Jean Le Pen, como candidato presidencial do Front National, ter ido para o segundo turno nas eleições de 2002 deve ser visto como uma evidência da crescente importância da imigração na França. Cabe dizer que o Front Nacional é um partido francês de extrema-direita, criado em 1972, que considera a imigração "um atentado contra a cultura e a economia francesa". A vitória eleitoral de Nicolas Sarkozy em 2007 não escapa também desse quadro, dado que como ex-Ministro do Interior, o atual presidente francês foi responsável por tornar a política migratória do país muito mais restritiva, reivindicando a "imigração escolhida e não sofrida pela França".

Resta saber até que ponto os brasileiros são "escolhidos" e quem são estes eleitos. Apesar de não haver ainda elementos capazes de sustentar considerações mais conclusivas, ao que parece, no contexto do fluxo Brasil-França há diversas modalidades migratórias que envolvem desde estudantes financiados por agências brasileiras, passando por profissionais de empresas francesas atuantes no Brasil, até indivíduos com situação econômica mais precária e condição irregular naquele país. O desafio é melhor caracterizar esses imigrantes, descobrir quem são e como vivem, para então explorar analiticamente o tipo de seletividade migratória que atua nas distintas modalidades migratórias que constituem tal fluxo.

\section{Referências}

AMARAl, Ruy Pacheco de Azevedo. Ano do Brasil na França. Brasília: Fundação Alexandre de Gusmão, 2008.

BOURDIEU, Pierre. "Os três estados do capital cultural". In: NOGUEIRA, Maria Alice e CATANI, Afrânio. Escritos de educação. Petrópolis: Vozes, 1998. 
CANÊDO, Letícia e GARCIA, Afrânio. "Les boursiers brésiliens et l'accès aux formation d'excellence internacionales". Cahiers du Brésil Contemporain. № 57/58-59/60. Paris: CRBC, 2004-2005.

CHESNAIS, François. A mundialização do capital. São Paulo: Xamã, 1996.

KECHICHIAN, Melissa (coord). A presença francesa no Brasil: de Villegaignon ao século XXI. São Paulo: Editora Conteúdo, 2009.

MARTINS, Carlos Benedito (org). Diálogos entre o Brasil e a França: formação e cooperação acadêmica. Recife:

Fundação Joaquim Nabuco, Ed. Massangana, 2005.

MASSEY, D. et al. Return to Aztlan: the social process of international migration from western Mexico. Los Angeles: University of California Press, 1987.

MAZZA, Débora. "Intercâmbios acadêmicos internacionais: bolsas Capes, CNPq e Fapesp". Cadernos de Pesquisa, v. 39, n. 137, mai/ago 2009.

MUÑOZ, Marie-Claude. "La mobilité internationale à destination de la France: objectivation des parcours et expérience existentielle". Cahiers de la recherche sur l'éducation et les savoirs. n. 2. Bondy: ARES, 2009.

PORTES, Alejandro. Migrações internacionais: origens, tipos e modos de incorporação. Oeiras: Celta, 1999.

REIS, Rossana Rocha. "Políticas de nacionalidade e políticas de imigração na França". In: Revista Brasileira de Ciências Sociais, v. 14, n. 32, fev, 1999.

ROBERTS, Bryan R. "Socially expected durations and the economic adjustment of immigrants". In: PORTES, Alejandro (ed) The economic sociology of immigration. New York: Russell Sage Fundation, 1995. 
SASSEN, Saskia. La movilidad del trabajo y del capital. Madri: Ministério de Trabajo y Seguridad Social, 1993.

SINGER, Paul. “Migrações internas: considerações teóricas sobre seu estudo". In: Economia política da urbanização. São Paulo: Brasiliense, 1973.

SOARES, Weber. "Análise de redes sociais e os fundamentos teóricos da migração internacional". In: Revista Brasileira de Estudos Populacionais, v. 21, n. 1, jan/jun, 2004.

TAVARES, Aurélio de Lyra. Brasil-França: ao longo de cinco séculos. Rio de Janeiro: Biblioteca do Exército, 1979.

XAVIER DE BRITO, Angela. "Transformações institucionais e características sociais dos estudantes brasileiros na França" In: BIB - Revista Brasileira de Informação Bibliográfica em Ciências Sociais, n. 50, 2000. 